DENHAM : THE METHYLATION OF CELLULOSE, PART III. 77

\title{
VII.-The Methylation of Cellulose. Part III. Homogeneity of Product and Limit of Methylation.
}

\section{By William Smith Denham.}

In previous papers (Denham and Woodhouse, T., 1913, 103, 1735; $1914,105,2357 ; 1917,111,244)$, the methylation of cellulose and of starch was announced, and some results were communicated of an investigation on the methyl ethers of cellulose and their hydrolytic products. The latter include a well-defined, crystalline trimethyl glucose, to which a constitutional formula has been assigned. Immediate aims in the development of this research have been the preparation of a methyl ether of maximum methoxyl content, in which the cellulose complex shall have undergone the minimum of degradation, and the examination of the limiting and intermediate ethers and their degradation products. It is proposed to amplify and discuss in a subsequent communication the additional results now presented.

For the preparation of a highly methylated cellulose, the method already described, namely, the treatment with methyl sulphate of cotton which has been soaked in a solution of sodium hydroxide, was found to be the most successful, and repetitions of this process, variously modified, have yielded a product containing $44 \cdot 6$ per cent. of methoxyl. This value approximates to the $45 \cdot 6$ per cent. of methoxyl required by theory for trimethyl cellulose. The slow rate of increase in the methoxyl content during the final stages of the methylation, itself an indication that the limit has been nearly approached, has rendered advisable the additional observations now in progress before the limit can be definitely announced. That these ethers retain a high degree of complexity is indicated by the almost complete absence of copper-reducing property in a product containing about 40 per cent. of methoxyl, in which, as in more highly methylated preparations, the fibrous structure of cellulose persists. Further, the displacement of hydrogen by methyl groups does not confer solubility in such solvents as alcohol, acetone, or chloroform.

The solubility of methylated cellulose in Schweitzer's reagent, on the other hand, appears to decrease as the methoxyl content increases, and products which contain about 40 per cent. of methoxyl are insoluble. The question of the homogeneity of methylated cellulose is of great importance in relation to deductions regarding the constitution of cellulose from the nature 
of the hydrolytic products, and some experiments which give information on this point may therefore be referred to, although they were made primarily to ascertain whether, by the restricted action of Schweitzer's reagent especially on preparations of low average methoxyl content, a highly methylated portion could be separated to serve as a convenient source of the crystalline trimethyl glucose. It was found that several preparations of methyl cellulose, when treated with Schweitzer's reagent so that only a part was dissolved, yielded a residue with a methoxyl content greater than that of the untreated substance. The degree of heterogeneity thus revealed depends, as might be expected, on the manner of preparation of the methyl cellulose; for material of low average methoxyl content, it was greatest where concentrated alkali had been employed, possibly owing to an unequal penetration of the cotton by the alkali. The most homogeneous product of those examined was one in the preparation of which an ethereal solution of methyl sulphate was employed, and it may be noted that the best yields, apparent in an increased weight of material after methylation, were obtained when ether was present. A preparation containing about 40 per cent. of methoxyl gave indications of lack of uniformity explicable from its history; one containing 42 per cent. of methoxyl was quite insoluble in Schweitzer's reagent, and in alcohol, acetone, or chloroform, and is therefore so far homogeneous.

A comparison of the history of the sample of methylated cellulose which yielded the hydrolytic products, already described and discussed (T., 1914, 105, 2357), with the histories of the preparations made without ether, which were examined by means of Schweitzer's reagent, indicates a superior uniformity in the earlier product, as in the later ones there were fewer stages in the methylation. It is thus probable that the trimethyl glucose was derived, not from a small proportion of highly methylated substance, but from a more general distribution of trimethyl glucose residues in the cellulose complex.

As the limit is approached, irregularities in methylation will be smoothed out, but the question of yield remains. The loss of material due to chemical action need not be great. In one series, 100 grams of cotton gave 104 grams of methyl cellulose containing 31.3 per cent. of methoxyl, the yield being thus 91 per cent. of the theoretical; the product had undergone four treatments, that is, it had been soaked in alkali, treated with methyl sulphate, and washed and dried four times, so that at least a part of the loss was mechanical. Owing to losses due to mishaps, the yields have not been followed continuously to the highest degree of methylation attained; the loss is small, however, from stage to stage, and 
is usually quite clearly mechanical loss sustained in manipulation.

The conclusions seem to be justified that the limit of methylation of cellulose lies in the neighbourhood of that required for trimethyl cellulose, and that a methyl cellulose of this limiting methoxyl content can be prepared which is representative of the whole of the original cellulose. The further investigation of these questions and of the fission products of methyl cellulose is in progress.

EXPEIMENTAL.

The following examples illustrate the yields obtained in several preparations of methyl cellulose and the behaviour of the products towards Schweitzer's reagent.

I. Methyl Cellulose containing $20^{\circ} 4$ per cent. of Methoxyl.The solution of sodium hydroxide employed contained 20 grams of the solid in 100.c.c. of solution. No solvent was employed for the methyl sulphate, slightly more of which was added than is represented by the ratio $\mathrm{Me}_{2} \mathrm{SO}_{4}: \mathrm{NaOH}$. In each stage the temperature rose to $70^{\circ}$ during the reaction, and the mixture was afterwards warmed gently until acid throughout.

1st Stage.-165 Grams of cotton wool, 500 c.c. of sodium hydroxide solution, 390 grams of methyl sulphate. Yield, 135 grams. Methoxyl content not determined.

2nd Stage.-135 Grams of the product from the first stage, 400 c.c. of sodium hydroxide solution, 236 grams of methyl sulphate. Yield, 98 grams. $\mathrm{OMe}=20.4$ per cent.

Action of Schweitzer's Reagent.-The product from the second stage, after remaining for seven days with 4 litres of Schweitzer's reagent, left 42 grams of undissolved residue containing $\mathrm{OMe}=22.7$ per cent. Three quantities of 3 grams each of the substance containing $\mathrm{OMe}=22 \cdot 7$ per cent. were again treated each with 170 c.c. of Schweitzer's reagent:

(a) Residue after two days (1.5 grams) contained $\mathrm{OMe}=23.1$ per cent.

(b) Residue after five days (1.3 grams) contained $\mathrm{OMe}=24.3$ per cent.

(c) Residue after seven days (1.3 grams) contained $\mathrm{OMe}=24 \cdot 7$ per cent.

The mixed residues were completely soluble in Schweitzer's reagent.

(d) By the action of Schweitzer's reagent on 28 grams of the substance containing $\mathrm{OMe}=22 \cdot 7$ per cent., $4 \cdot 4$ grams of undissolved residue were obtained which contained $\mathrm{OMe}=23.4$ per cent. The 4.4 grams were again treated with Schweitzer's reagent so as to leave a small residue (weight not determined) which contained $\mathrm{OMe}=28$ per cent. 
The Schweitzer s reagent was prepared by shaking freshly pre. cipitated copper hydroxide with concentrated aqueous ammonia (D 0.88 ), and had $\mathrm{D}$ about 0.93 . It was not standardised as regards content of ammonia or copper, but the reagent was tested to make sure that it dissolved cotton. The undissolved cellulosic residue was recovered by diluting the solution with aqueous ammonia, filtration through nickel gauze, and washing with aqueous ammonia and water. Small quantities were recovered by allowing the filtered solution to settle.

The methyl cellulose, the hydrolytic products from which have been described (T., 1914, 105, 2357), was prepared in six stages; in the first five, the solution of sodium hydroxide contained 17 grams of the solid in 100 c.c., and the product contained $\mathrm{OMe}=20 \cdot 7$ per cent. In the final stage the sodium hydroxide solution contained 38.3 grams of the solid in 100 c.c., and the product contained $\mathrm{OMe}=23 \cdot 6$ per cent.

II. Methyl Cellulose containing $\mathrm{OMe}=39.5$ per cent.-This substance was prepared in nine stages. After three stages, in each of which the material was impregnated with half its weight of sodium hydroxide added as a solution containing 21.4 grams of the solid in 100 c.c., the OMe content was 24.8 per cent. In all the stages, somewhat less methyl sulphate was employed than is represented by the ratio $\mathrm{Me}_{2} \mathrm{SO}_{4}: \mathrm{NaOH}$, and the substance remained alkaline after the reaction was over. From 160 grams of cotton wool were obtained 135 grams, the yield being 79 per cent. of that obtainable of a product having $\mathrm{OMe}=24.8$ per cent.

In the later stages, the sodium hydroxide solution contained 38.8 grams of the solid in 100 c.c. Difficulties were encountered in impregnating the material with the alkaline solution, and the material was cut up into small pieces, squeezed in a press, pounded, etc., so that there was considerable loss. The percentage of methoxyl remained stationary from the eighth to the ninth stage (OMe $=39 \cdot 7-39 \cdot 5$ per cent.).

Action of Schweitzer's Reagent.--2.8 Grams of the product containing $\mathrm{OMe}=39.5$ per cent,, after treatment with 50 c.c. of Schweitzer's reagent for four days, gave 2.6 grams of undissolved residue containing $\mathrm{OMe}=40$ per cent. ; 2.4 grams of this residue, on further treatment with Schweitzer's reagent, were reduced to $2 \cdot 2$ grams, which contained $\mathrm{OMe}=40 \cdot 4$ per cent.

Copper Reduction.-0.978 Gram of substance (OMe $=39.5$ per cent.) was treated with Fehling's solution, as in the examination of cotton. 0.15 C.c. of $N / 10$-sodium thiosulphate was required for the titration of the reduced copper. $\mathrm{Cu}_{2} \mathrm{O}=0.11$ per cent.

III. Preparation of Methyl Cellulose, using Ether.-One 
hundred grams of cotton wool were soaked for one day in 1 litre of a solution of sodium hydroxide (20 grams in 100 grams of solution), and then drained and pressed, so that 350 grams of the solution (containing 70 grams of sodium hydroxide) were left. One hundred c.c. of methyl sulphate and 700 c.c. of ether were added, the mixture was heated under reflux for a few hours, and the ether was then removed by distillation. The weight of the washed and dried product was 105 grams. A repetition of this process gave 107 grams of a product containing $\mathrm{OMe}=24.5$ per cent. In a third and fourth repetition of the process, where the impregnation of the material by the solution of alkali was assisted by exhausting the containing vessel, less sodium hydroxide was retained. The product from the fourth treatment contained $\mathrm{OMe}=31.3$ per cent. and weighed 104 grams, the yield being thus 91 per cent. of the theoretical. The weights were determined under similar conditions after drying the material in a steam-oven.

Action of Schweitzer's Reagent.-From 2.88 grams of substance $(\mathrm{OMe}=31.3$ per cent.), after immersion in 100 c.c. of Schweitzer's reagent for three hours, 1.93 grams of undissolved substance (OMe $=32 \cdot 4$ per cent.) were recovered.

Eighty-eight grams of methyl cellulose containing $\mathrm{OMe}=15 \cdot 6$ per cent., which had been made in one stage, using ether, were immersed in 600 c.c. of Schweitzer's reagent for three days, when 8.4 grams of undissolved material were recovered containing $\mathrm{OMe}=15 \cdot 2$ per cent.

IV. Methyl Cellulose containing more than 40 per cent. of Methoxyl.-Highly methylated products were prepared by variants of the methods already described. For one of these, the following analytical results were obtained (Found: $\mathrm{C}=52 \cdot 19$; $\mathrm{H}=7 \cdot 63 ; \mathrm{OMe}=44 \cdot 6$ per cent. Trimethyl cellulose, $\mathrm{C}_{9} \mathrm{H}_{16} \mathrm{O}_{5}$, requires $\mathrm{C}=52 \cdot 9 ; \mathrm{H}=7 \cdot 84 ; \mathrm{OMe}=45 \cdot 6$ per cent.).

Action of Solvents. - The behaviour of a preparation containing $\mathrm{OMe}=42$ per cent. was examined towards alcohol, acetone, and Schweitzer's reagent. 1.8802 Grams, after being extracted with alcohol for three hours in a modified Soxhlet apparatus, weighed 1.8796 grams. The same sample was then extracted in the same way with acetone for three hours, and afterwards weighed 1.8790 grams. 0.408 Gram of the same substance was immersed in Schweitzer's reagent for twenty-four hours; the weight of the undissolved substance recovered was 0.407 gram.

Chemistry Department,

St. Mary's Hospital Medical Schoot,

Paddington, W. 2.

[Received November, 29th, 1920.] 